\title{
Investigation of the factors related to low birth weight in the south of Iran: a case-control study
}

\author{
Rajizadeh A., BS ${ }^{1}$, Samimi Sh., MD², Momeni M., MD ${ }^{3,4}$ \\ 1. Senior Researcher, Health Services Management Research Center, Institute for Futures Studies in Health, Kerman \\ University of Medical Sciences, Kerman, Iran. \\ 2. General Practitioner, Jiroft University of Medical Sciences, Jiroft, Kerman, Iran. \\ 3. Assistant Professor, Department of Community Medicine, Social Determinants of Health Research Center, Institute for \\ Futures Studies in Health, Kerman University of Medical Sciences, Kerman, Iran. \\ 4. Assistant Professor, Department of Community Medicine, Jiroft University of Medical Sciences, Jiroft, Kerman, Iran \\ (Corresponding Author),Tel :+98-34-33257313, m.momeni@kmu.ac.ir
}

\begin{abstract}
Background and Aim: Since birth weight is one of the most important health indicators, we decided to investigate the factors related to the low birth weight (LBW) of the infants in the south of Kerman Province.

Material and Method: This case-control study included 300 cases of neonates in Jiroft City. 150 neonates with low birth weight (less than $2500 \mathrm{~g}$ ) were placed in the case group and our control group included 150 neonates with normal birth weights. Data were extracted from the health documents of the neonates and categorized into four groups including demographic data of the parents, pregnancy data, parental risk behaviors and infant characteristics. Using SPSS software version 20, data were analyzed by single and multivariate logistic regression.

Results: Single-variable regression analysis showed the possibility of having LBW neonate was higher in the mothers over 35 years of age, or with a history of illness, smoking and drug abuse compared to the neonates in other groups. Also, poor care, old age of fathers and high maternal weight were associated with an increased rate of LBW. Multivariate regression analysis revealed a significant difference between all the above - mentioned variables except the age of the fathers, in relation to LBW of the neonates. In addition, low birth weight was more likely in the babies born through cesarean section and neonates born to the mothers with high school diploma compared to the neonates in other groups.

Conclusion: Prevention of pregnancy at an older age, mothers' education about avoiding drug use and smoking, as well as prenatal care are suitable measures for prevention of LBW.
\end{abstract}

Keywords: Low birth weight, Pregnancy, Birth weight, Risk factor.

Received: Oct 24, 2017 Accepted: Apr 9, 2018 


\section{بررسى عوامل مرتبط با تولد نوزادان كموزن در جنوب ايران - يك مطالعه مورد شاهدى}

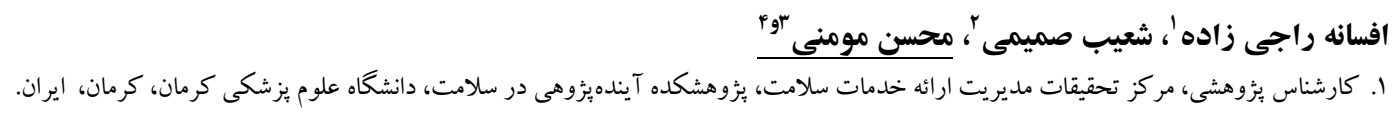

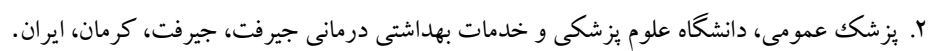

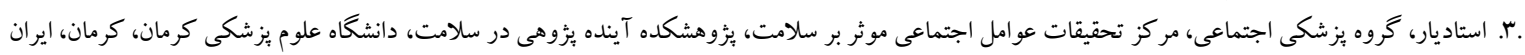

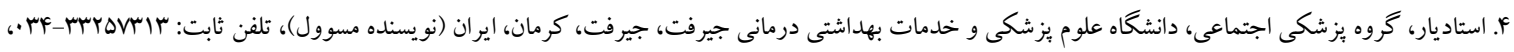
m.momeni@kmu.ac.ir

مقدمه: از آنجا كه وزن هنگام تولد يكى از شاخص هاى مهم بهداشتى مىباشد، لذا مطالعه حاضر باهدف بررسى عوامل مرتبط با

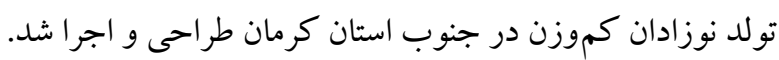

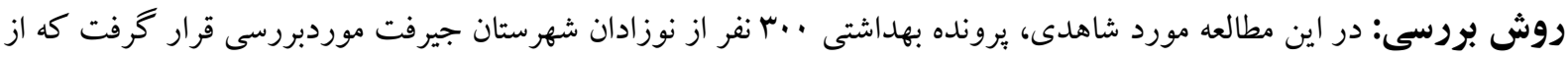

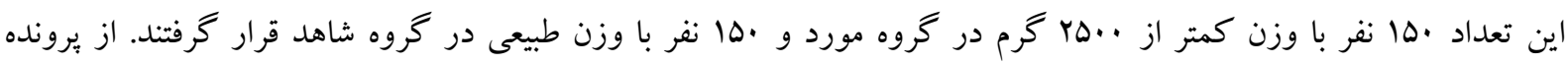

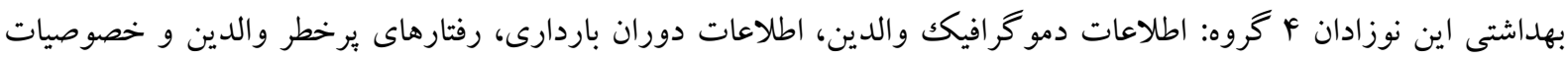

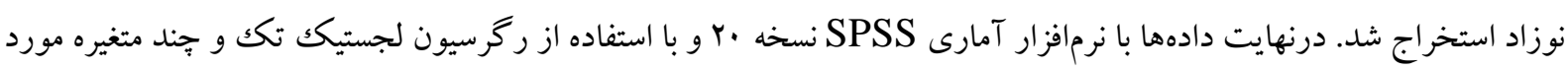
تحليل آمارى قرار گرفتند. يافته ها: در آناليز رگرسيون تكك متغيره احتمال تولد نوزاد كموزن در نوزادان با مادر بالاى هـ سال سن، سابقه بيمارى در مادر،

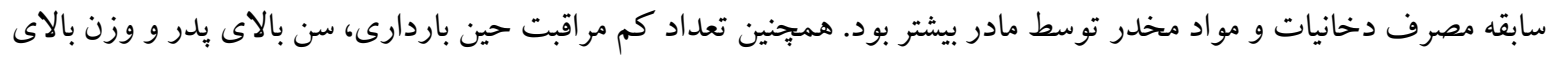

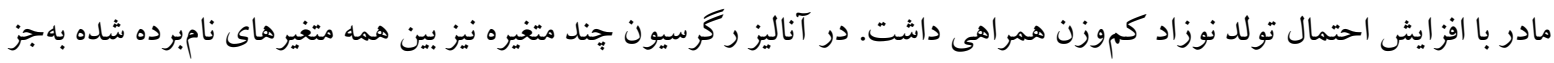

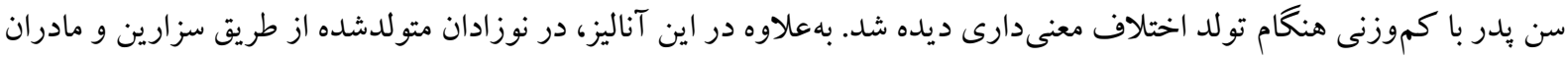

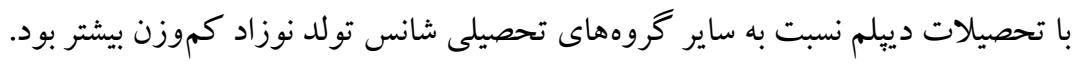

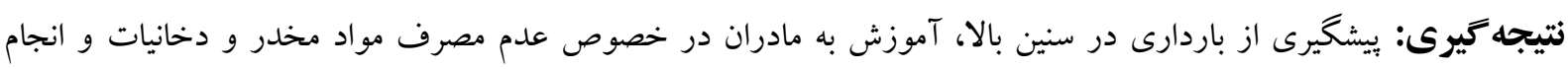

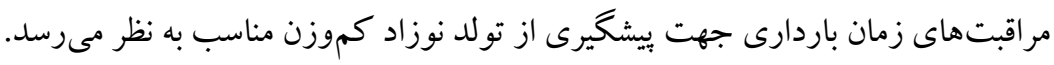

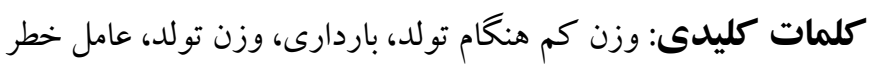

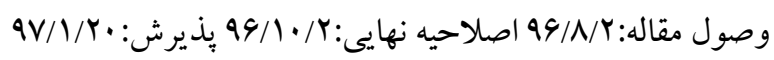


ارتباط وجود دارد(· · (V) كه همه اين شواهد لزوم توجه به وزن هنگام تولد را بررنگك تر مىنمايد.

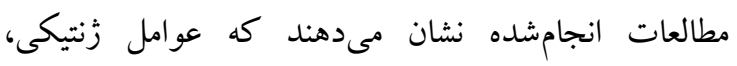
اجتماعى، بيولوزيكك و بهطور كلى هر عاملى كه بر سلامت

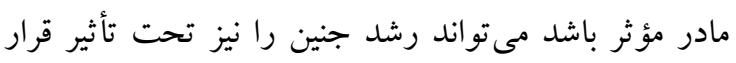

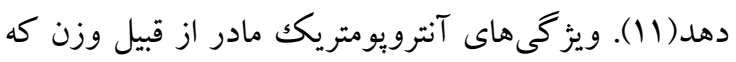

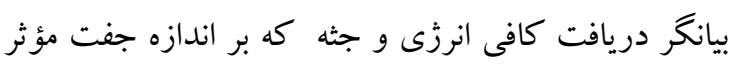
است مىتواند بهطور مستقيم بر وزن نوزاد اثر گذار باشند. شيوه زندكى مادر مانند استعمال دخانيات بهواسطه نيكوتين

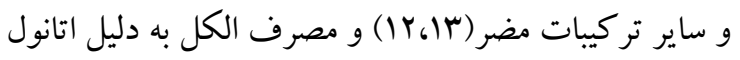
مىتواند سلامت جنين را تهديد كند(If). بعلاوه ساير عوامل مانند مصرف مكمل هاى ويتامينى توسط مادر، شغل و تحصيلات بدر و مادر و بسيارى از عوامل ديخر مى توانند

سلامت مادر و جنين هردو را تحت تأثير قرار دهند(r). ازجمله اهداف سازمان بهداشت جهانى تا سال هـr ك كاهش

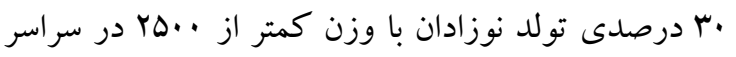

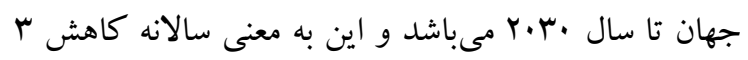

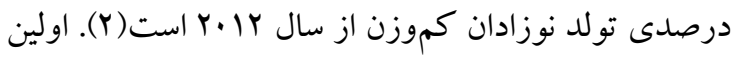
قدم براى رسيدن به اين هدف ارزيابى وضعيت موجود و ورد

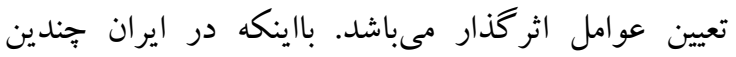
مطالعه در خصوص بررسى عوامل مؤثر بر وزن نوزاد

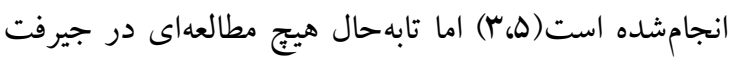
در اين زمينه صورت نخرفته است و ازآنجاكه عوامل اجتماعى، فرهنگى و آدابورسوم هر منطقه ازجمله عوامل

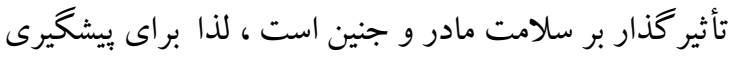
از تولد نوزادان كموزن و تدوين استراتزىهاى لازم مطالعه

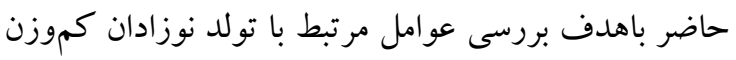
در جنوب استان كرمان طراحى و اجرا شد.

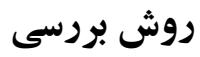

اين مطالعه تحليلى مورد سشاهدى از اول فروردينماه بوه تا

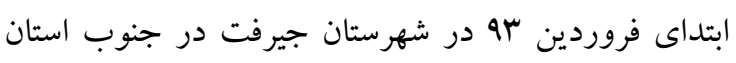

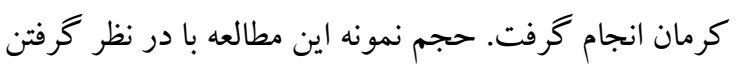

\section{مقدمه} وزن هنگام تولد يكى از شاخصهاى مهم ارزيابى سلامت

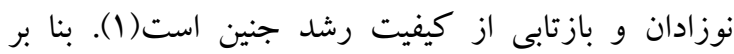
استاندارد سازمان جهانى بهداشت 'WHO)وزئ نرمال

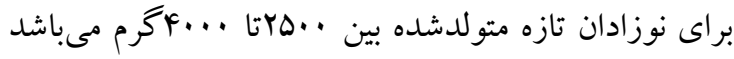

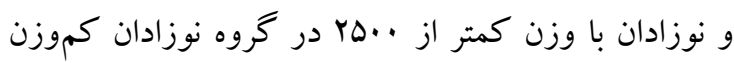

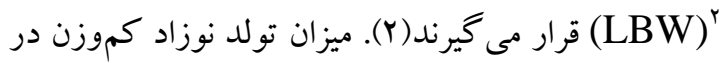

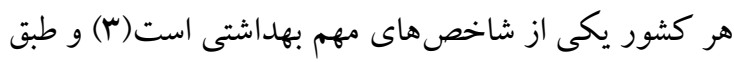

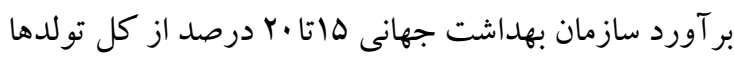

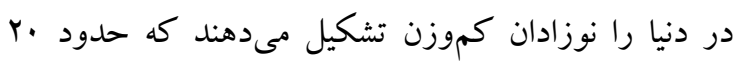
ميليون تولد در سال را شامل مىشود(Y). طبق گزارش

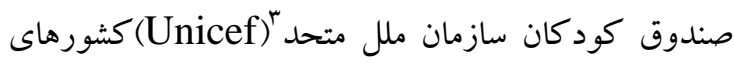
جنوب آسيا با نرخ ^Y درصد بيشترين شيوع تولد نوزادان

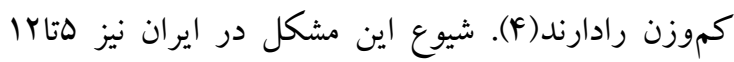

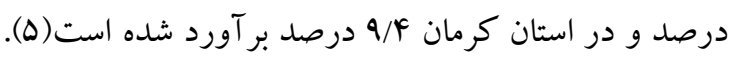

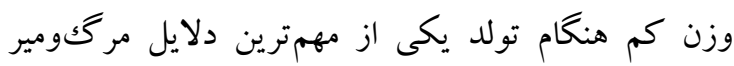

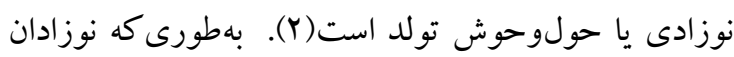
كموزن هنگام تولد نسبت به نوزادان با وزن طبيعى ·r بر برابر بيشتر در معرض خطر مر گك قرار دارند (9).

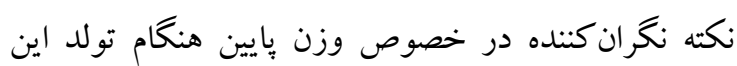
است كه عوارض آن فقط محدود به حولوحوش تولد نبوده و بسيارى از بيمارىهاى مزمن در بزرگكسالى منشأ جنينى

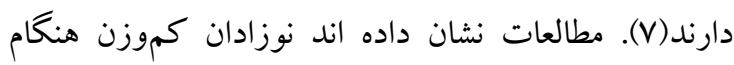

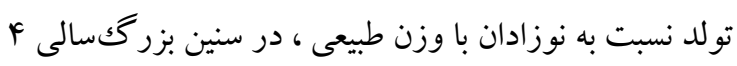
برابر بيشتر در معرض ابتلا به اختلالات جربى خون قرار

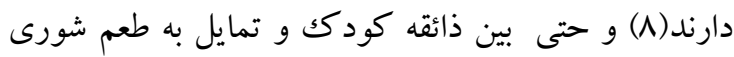
با وزن هنگام تولد نيز ارتباط معنىدارى ديدهشده است(9). بهعلاوه بين مشكلات ديخرى از قبيل كاهش حساسيت به ونه انسولين، فشارخون و احتمال ابتلا به بيمارىهاى روانى از

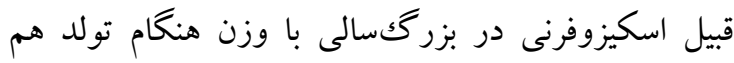

\footnotetext{
${ }^{1}$ World Health Organization

${ }^{2}$ Low Birth Weight

${ }^{3}$ United Nations Children's Fund
} 
كمخونى، بيمارىهاى مقاربتى)، مصرف مكمل در دوران

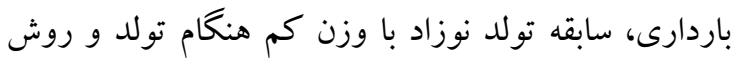

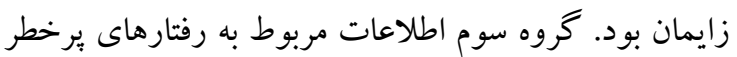

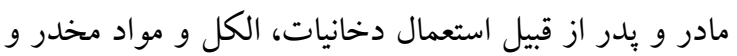
كروه آخر نيز مربوط به اطلاعات نوزاد از قبيل جنس و وزن بود. لازم به ذكر است اطلاعات استخر اجشده و هويت افراد تا بايان مطالعه بهصورت كاملاً محرمانه نخههدارى شد.

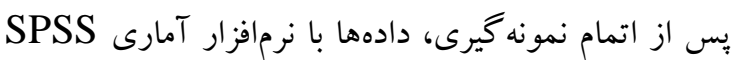

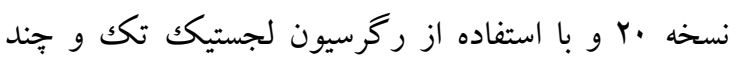
متغيره جهت بررسى اثر همزمان متغيرها و ويشبينى تأثير

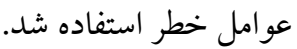

\section{يافته ها}

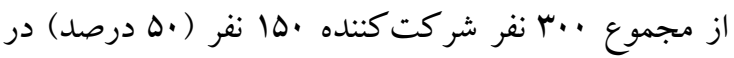

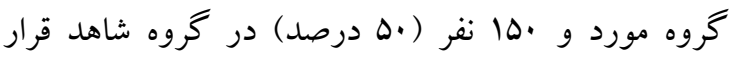
داشتند. ميانگين سنى مادران موردمطالعه •9/9

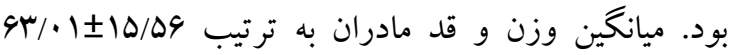

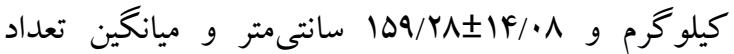

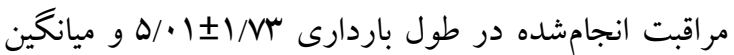

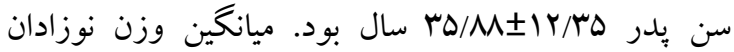

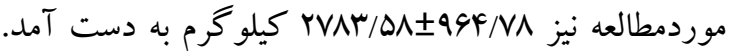

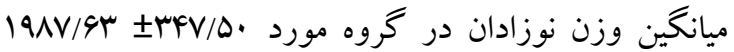
گرم و در گروه شاهد

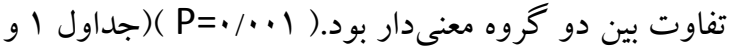

همجنين اثر همزمان متغيرها و يِيشينى تأثير عوامل خطر با استفاده از ركرسيون لجستيك تكك متغيره و جند متغيره موردبررسى قرار گرفت كه نتايج آن در جدول بـ نشان
خطاى نوع اول هـ/ •، توان مطالعه A/ •، شيوع عوامل خطر

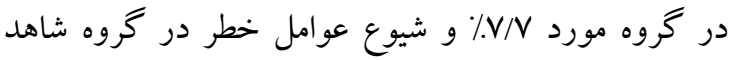

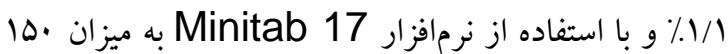
نفر در هر خروه محاسبه گرديد(ه|). براى انتخاب شر كت كنند گان در مطالعه، برونده بهداشتى زنانى كه در سال זو نوزاد تازه متولدشده داشتند موردبررسى قرار گرفت

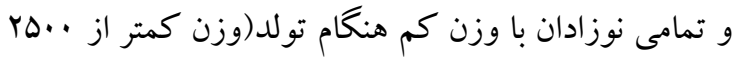

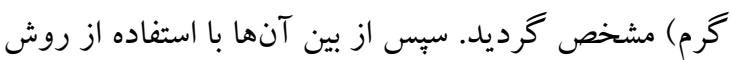

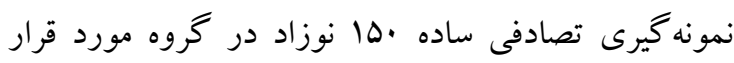

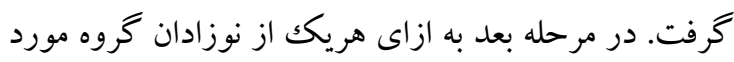

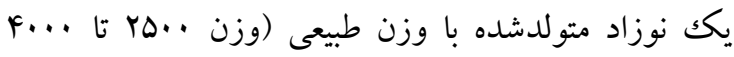

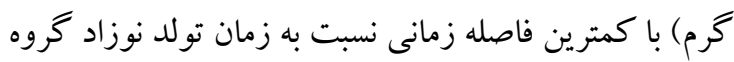

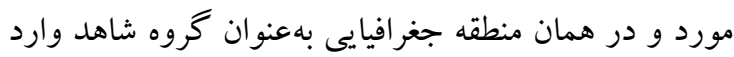

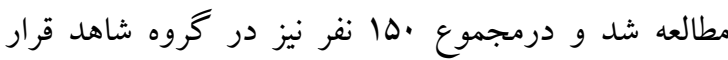

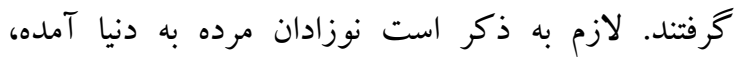
زايمانهاى دوقلويى و يا جند قلوبى، نوزادان با بيمارىهاى

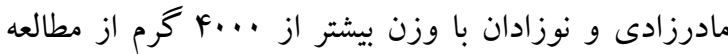

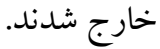
قبل از شروع مطالعه ابتدا اين طرح در كميته يُوهش

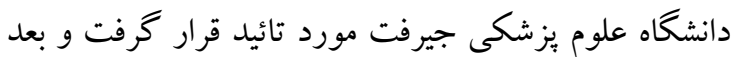
از كسب مجوز لازم از دانشكاه، با تمامى مراكز بهداشتى درمانى و وِايخاههاى بهداشتى شهر جيرفت جهت نمونه گيرى، هماهنگ لازم به عمل آمد. سبس با مراجعه كارشناسان آموزشديده به اين مراكز، نوزادانى كه داراى معيارهاى ورود بودند دريكى از دو گروه مورد يا شاهد قرار

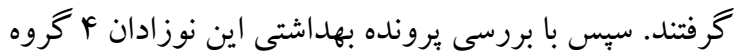
اطلاعات استخراج شد. گروه اول شامل اطلاعات دمو كرافيك،، اقتصادى و اجتماعى، سن، تحصيلات و شغل والدين نوزاد و وزن، قد مادر و تحت بوشش بيمه بودن مادر

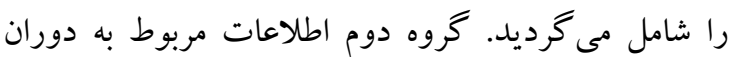
باردارى از قبيل تعداد مراقبت توسط مراقبين سيستم بهداشتى، سابقه بيمارىهاى مادر (فشارخون، بيمارىهاى تيروئيد، ديابت باردارى، ايدز، بيمارىهاى قلبى عروقى، 


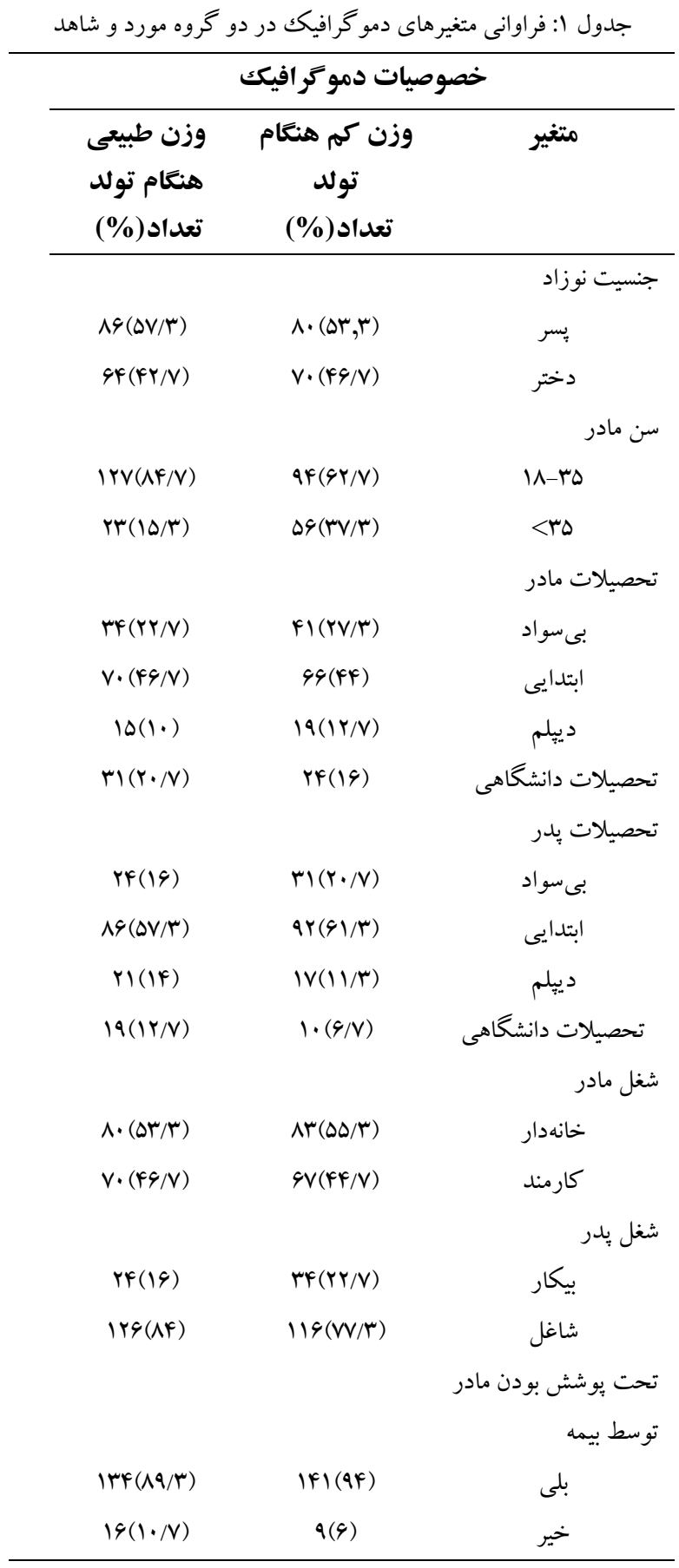




\begin{tabular}{|c|c|c|}
\hline \multicolumn{3}{|c|}{ خصوصيات بارورى } \\
\hline وزن طبيعى & وزن كم هنغام & \multirow[t]{3}{*}{ متغير } \\
\hline هنغام تولد & تولد & \\
\hline تعداد(\%) & تعداد(\%) & \\
\hline & & روش زايمان \\
\hline $99(99)$ & $\Lambda F(\Delta \varphi)$ & طبيعى \\
\hline \multirow[t]{2}{*}{$\Delta I(H F)$} & $99(F F)$ & سزارين \\
\hline & & سابقه بيمارى مادر \\
\hline$r \Delta(r \mu / T)$ & $\Delta r(r \Delta / r)$ & بلى \\
\hline \multirow[t]{2}{*}{$110(V 9 / V)$} & $9 V(G F / V)$ & 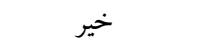 \\
\hline & & سابقه نوزاد كموزن \\
\hline$r V(\mid \Lambda)$ & $r \Delta(Y \mu / r)$ & بلى \\
\hline \multirow[t]{2}{*}{$\operatorname{Irr}(A Y)$} & $11 \Delta(V G / V)$ & خير \\
\hline & & مصرف مكمل \\
\hline $14 q(99 / \Gamma)$ & $\operatorname{IFF}(99)$ & بلى بلى \\
\hline \multirow[t]{2}{*}{$I(\cdot / \mathrm{V})$} & $q(f)$ & خير \\
\hline & & استعمال دخانيات \\
\hline $10(1 \cdot)$ & $r q(Y \varphi)$ & بلى \\
\hline \multirow[t]{2}{*}{$1 r \Delta(q \cdot)$} & $111\left(V^{f}\right)$ & خير \\
\hline & & استعمال مو اد مخدر \\
\hline $\mathbb{M}(\Lambda)$ & $M(Y Y)$ & بلى \\
\hline \multirow[t]{2}{*}{$\mid r \wedge(9 Y)$} & $\operatorname{llV}(\mathrm{VA})$ & خير \\
\hline & & مصرف الكل \\
\hline $\operatorname{IV}(\mid 1 / \Gamma)$ & $r Y(I F / V)$ & بلى بلى \\
\hline $\operatorname{lrm}(\mathrm{MN} / \mathrm{V})$ & $\mid r \wedge(\Lambda \Delta / \Gamma)$ & خير ير \\
\hline
\end{tabular}

كيلو گرم افزايش وزن مادر شانس تولد نوزاد كموزن Y+// برابر افزايش يافت [ب//1-1:1] افزايش مراقبت در زمان باردارى شانس تولد نوزاد كموزن

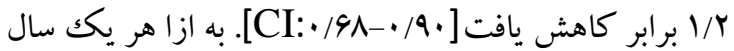
افزايش سن بدر نيز شانس تولد نوزاد كموزن r •/ برابر

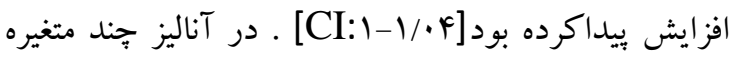
نيز بين همه متغيرهاى نامبرده شده در آناليز تكك متغيره بهجز سن بدر با وزن نوزاد اختلاف معنىدارى ديده شد. بعلاوه تحصيلات مادر باليكه در آناليز تكك متغيره معنىدار نبود اما در آناليز جِند متغيره نشان داده شد كه احتمال تولد نوزاد
در آناليز تكك متغيره احتمال تولد نوزاد كموزن در نوزادانى كه مادرشان بالاى هـ سال سن داشت نسبت به گروه نرمال

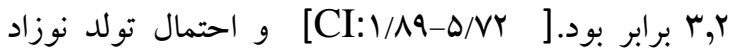
كموزن در مادرانى كه سابقه بيمارى داشتند نسبت به مادرانى كه سابقه بيمارى نداشتهاند نيز 1/99 برابر بود [CI: I/^-Y/AV] مادرانى كه سيگارى بودند نسبت به مادران غير سيگارى //

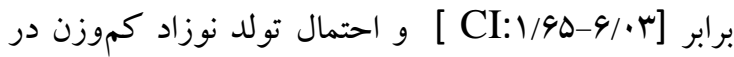
مادرانى كه مواد مخدر مصرف مى كردند نسبت به مادران

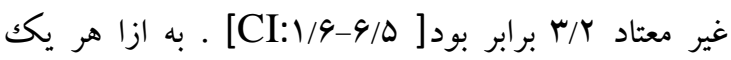


بود[CI:0.29-0.94] نتايج نهايى نشان داد كه مصرف مواد مخدر توسط مادر و سن مادر بيشترين متغيرهاى تأثير گذار بر احتمال تولد نوزاد كموزن بود و در مقابل وزن مادر كمترين ارتباط را با تولد نوزاد كموزن داشت.
كموزن در نوزادانى كه مادرشان دييلم دارند نسبت به مادرانى كه تحصيلات دانشكاهى دارند ب/F برابر بيشتر بود

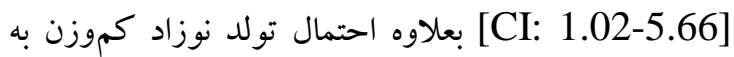
روش سزارين 1/9 برابر بيشتر از تولد به روش طبيعى

\begin{tabular}{|c|c|c|c|c|}
\hline \multicolumn{2}{|c|}{ تعديل يافته } & \multicolumn{3}{|c|}{ خام } \\
\hline $\boldsymbol{P}_{V}$ & OR(\%95 C.I) & $\boldsymbol{P}_{V}$ & OR(\%95 C.I) & متغير \\
\hline & & & & جنسيت نوزاد \\
\hline & گروه رفرنس & & خروه رفرنس & 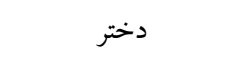 \\
\hline$\cdot / 4$ & $\cdot / \mathrm{V}(\cdot / / 4 F-1 / \mu \Lambda)$ & $\cdot / 4 \Lambda$ & $\cdot / \Delta \Delta(\cdot / \Delta r-1 / N \psi)$ & 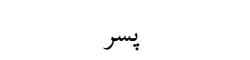 \\
\hline & & & & سن مادر \\
\hline & كروه رفرنس & & گروه رفرنس & M-ro \\
\hline$\cdot / \cdot \cdot$ & $F / \mid r(r /|Y-V / q|)$ &.$/ .1$ & $r / r Q(1 / \wedge Q-\Delta / N r)$ & $r o<$ \\
\hline & & & & تحصيلات مادر \\
\hline & گرووه رفرنس & & گرووه رفرنس & تحصيلات دانشگاهى \\
\hline.$/ .4$ & $r / P I(1 / \cdot Y-\Delta / 99)$ & $\cdot / 49$ & $1 / 94(\cdot / 99-r / A V)$ & دييلم \\
\hline .110 & $1 / N F(\cdot / N \mid-r / V q)$ & $\cdot / \Delta F$ & $1 / Y I(\cdot / 9 \mathrm{~K}-\mathrm{Y} / \mathrm{TA})$ & ابتدايى \\
\hline.$/ 19$ & $r / I T(\cdot N T-G / Y q)$ & $\cdot|r|$ & $1 / \Delta \Delta(\cdot / W V-r / / r)$ & بـ سواد \\
\hline & & & & تحصيلات بدر \\
\hline & كروه رفرنس & & گروه رفرنس & تحصيلات دانشخاهى \\
\hline.$/ 11$ & $r / A F(\cdot / \Lambda \cdot-V / F r)$ & $\cdot / r q$ & $1 / \Delta r(\cdot / \Delta G-F / V V)$ & دييلم \\
\hline$\cdot / \mu$ & $1 / 94(\cdot / 9 T-F / Y q)$ & .1 .9 & $r / \cdot r(\cdot / \wedge q-F / q))$ & ابتدايى \\
\hline$\cdot / 4 V$ & $V / \Delta F(\cdot / F V-\Delta / \cdot V)$ & .1 .0 & $r / \& \Delta(\cdot / 99-9 / T r)$ & 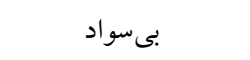 \\
\hline & & & & شغل مادر \\
\hline & گروه رفرنس & & گرووه رفرنس & كارمند \\
\hline . & $1 / \Delta r(\cdot / A V-r / G V)$ & $\cdot / v r$ & $1 / \cdot N(\cdot / 9 \Lambda-1 / N \cdot)$ & خانهدار \\
\hline & & & & شغل بدر \\
\hline & گرووه رفرنس & & كروه رفرنس & بيكار \\
\hline.$/ 0$ & $1 / Y V(\cdot / 9 T-Y / \Delta V)$ & $1 / \Delta r$ & $1 / \Delta r(\cdot / \Lambda 9-Y / N F)$ & شاغل \\
\hline & & & & تحت بوشش بيمه بودن \\
\hline & & & & مادر ماد \\
\hline & گروه رفرنس & & خروه رفرنس & بلى بل \\
\hline .1 & $\cdot / 4 \mu(\cdot / 1 \Delta-1 / 1 \Lambda)$ & $\cdot / 1 F$ & $1 / N V(\cdot / V Q-F / R V)$ & خير \\
\hline & & & & روش زايمان \\
\hline & كروه رفرنس & & كروه رفرنس & سزارين ل \\
\hline.$/ r$ & $\cdot / \Delta r(\cdot / r q-\cdot / Q Y)$ & $\cdot / v$ &.$/ 90(\cdot / 41-1 / .4)$ & طبيعى \\
\hline
\end{tabular}




\begin{tabular}{|c|c|c|c|c|}
\hline & گروه رفرنس & & گروه رفرنس & خير \\
\hline \multirow[t]{4}{*}{.$/ \cdot 1$} & $r / Y \Gamma(1 / M-F / Y r)$ & $\cdot / \cdot r$ & $1 / V 9(1 / \cdot \Lambda-Y / 9 \vee)$ & بلى بلى \\
\hline & & & & سابقه تولد نوزاد \\
\hline & & & & كم وزن \\
\hline & گَروه رفرنس & & گرووه رفرنس & خير \\
\hline \multirow[t]{3}{*}{ 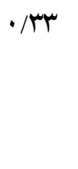 } & $1 / \Gamma q(\cdot / V \cdot-r / V q)$ & $\cdot / r \Delta$ & $1 / \Gamma \wedge(\cdot / V q-Y / \& r)$ & بلى بلى \\
\hline & & & & مصرف مكمل \\
\hline & گروه رفرنس & & گروه رفرنس & بلى \\
\hline \multirow[t]{3}{*}{$\cdot / M F$} & $F / Y Y(\cdot / r G-F N / N q)$ & .1 .9 &.$/ 19(\cdot / \cdot 1-1 / r \Delta)$ & خير \\
\hline & & & & استعمال دخانيات \\
\hline & گَروه رفرنس & & گروه رفرنس & خير \\
\hline \multirow[t]{3}{*}{ •/ r } & $r / 1 V(1 / 01-9 / 99)$ &.$/ \cdot 1$ & $r / 19(1 / 90-9 / \cdot r)$ & بلى بلى \\
\hline & & & & استعمال مواد مخدر \\
\hline & گروه رفرنس & & گروه رفرنس & خير \\
\hline \multirow[t]{3}{*}{$\cdot / \cdot \cdot 1$} & $F / A Y(Y / \cdot V-11 / Y q)$ &.$/ \cdot 1$ & $\operatorname{r/YF}(1 / 9-9 / 0)$ & بلى بلى \\
\hline & & & & \\
\hline & كروه رفرنس & & كروه رفرنس & خير \\
\hline$\cdot / \Lambda$ & $1 / 1 Y(\cdot / \Delta \Lambda-Y / V F)$ & $\cdot / 4 q$ & $1 / r F(\cdot / 9 \Lambda-r / 94)$ & بلى بلى \\
\hline$\cdot / \cdot r$ & $1 / \cdot r(\cdot / \Delta \Lambda-r / V F)$ &.$/ \cdot f$ & $1 / \cdot r(1-1 / \cdot r)$ & وزن مادر \\
\hline - (rt & $1 / \cdot 1(\cdot / 99-1 / \cdot r)$ & $\cdot / 1$ & $1 / \cdot 1(\cdot / 99-1 / \cdot r)$ & قد مادر \\
\hline .1 .94 & $\cdot / \mathrm{V}(\cdot / 99-\cdot / 94)$ &.$/ \cdot 1$ & $\cdot / \mathrm{V} \Lambda(\cdot / 9 \Lambda-\cdot / 9 \cdot)$ & تعداد مر اقبت \\
\hline$\cdot / r$ &.$/ \cdot 1(\cdot / 99-1 / \cdot r)$ & .109 & $1 / \cdot r(1-1 / \cdot F)$ & سن بدر \\
\hline
\end{tabular}

در كرمان نيز نتيجه مشابهى داشت. در مطالعه ديخرى از بحث Momeni طبق نتايج بهدست آمده باردارى در سنين بالاى هr سال

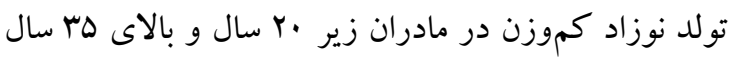

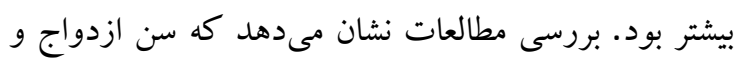

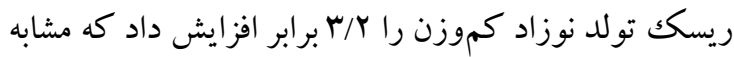
اين نتيجه در مطالعات ديخر نيز مشاهده شد. نتايج مطالعه رونه

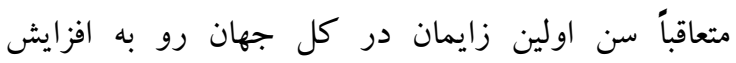
Kheirouri

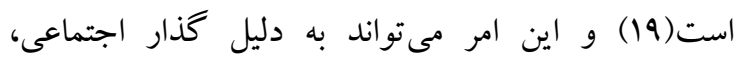
جمعيتى و تمايل زنان به كار و تحصيل يا به دليل استفاده

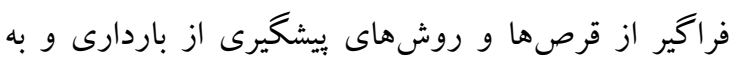
تعويق انداختن باردارى باشد درهرصورت مطالعات مرورى و كوهورت نشان دادهاند با افزايش سن مادر يتانسيل رشد بـ

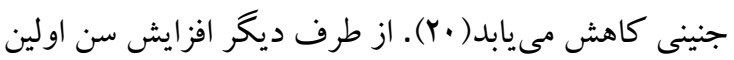
زايمان ريسك ابتلاى مادر به عوارض ناخواسته باردارى ماند ديابت باردارى، فشارخون، مرده زايى افزايش مىدهد

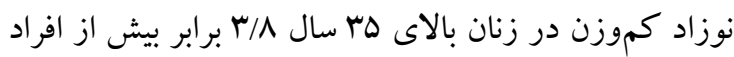

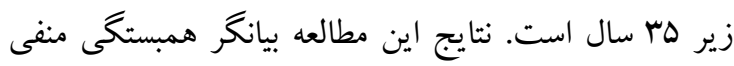

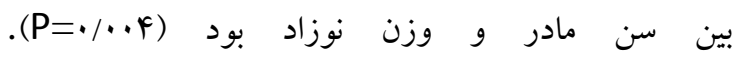
Mohammad

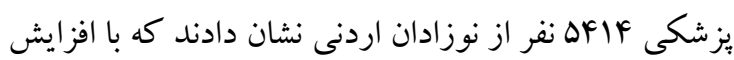

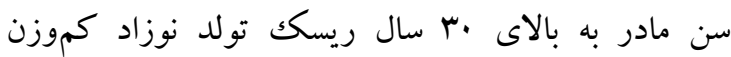

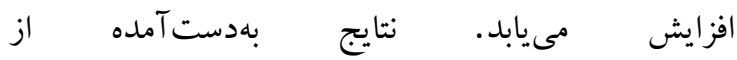

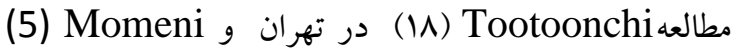


برنامهريزى جنينى و محيط نامطلوب رحمى در طول دوره حساس رشد جنينى مىتواند بر وزن هنكام تولد نوزاد اثر كذار باشد و اين امر برافزايش ريسك ابتلا به بيمارىهاى

قلبى عروقى در دورههاى بعدى زندكى نيز مؤثر است(V).

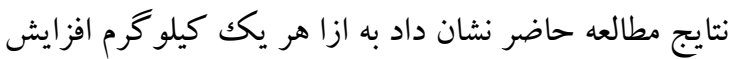

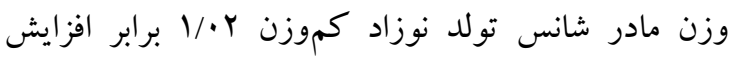
مى يابد. بررسى مطالعات مشابه نتيجه متناقضى را نشان داد

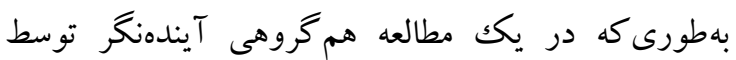
Haugen و همكاران نشان داده شد كه وزن گيرى زياد

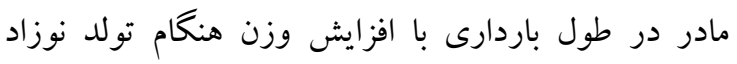
مرتبط است(YY). نتايج يكك مرور سيستماتيك هم نشان داد باد كه زنانى كه وزن گيرى بيشترى در طى باردارى دارند

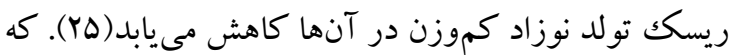
هردوى اين مطالعات نتيجهاى كاملاً متفاوت بامطالعه حاضر داشتند. شايد اين تناقض به اين دليل است كه در مطالعه

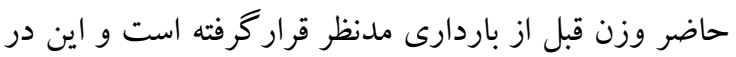
حالى است كه ميزان وزن گيرى مادر در زمان باردارى تأثير

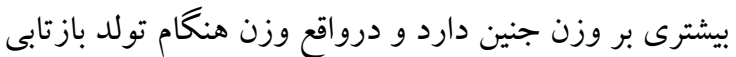

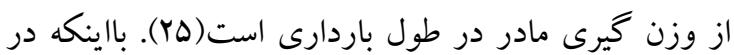
مطالعات مختلف بر وزن گيرى طبيعى مادر در باردارى تأكيد شده است و انحراف از محدوده نرمال در هر دو جهت نامطلوب مىباشد ، اما در دهلهاى اخير شيوع رو به افزايش اضافهوزن و جاقى در زنان سن باردارى به يكك نخر انى جدى تبديل شده است(YF). مطالعات جديدتر نشان داده است كه توده جربى با آزاد كردن برخى از سايتو كينهاى التهابى در بروز عوارض باردارى مانند يره

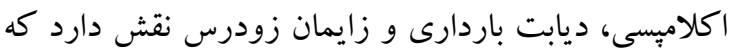
اين امر مىتو اند سلامت جنين و مادر را تحت تأثير قرار دهد

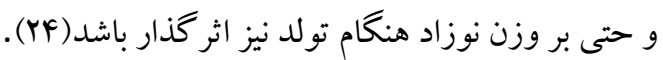

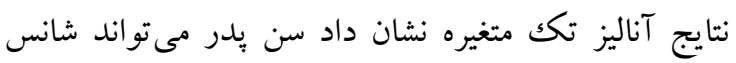
تولد نوزاد كموزن را ץ./ برابر افزايش دهد. يكك مطالعه دئه

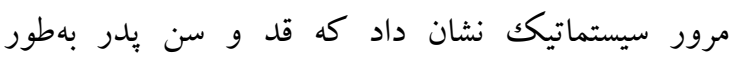
معنى
و بروز اين عوارض بر رشد جنين و وزن تولد مؤثر است(19). بهطورى كه در مطالعه حاضر در مادرانى كه

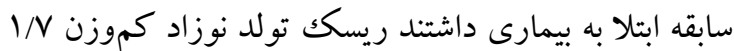
برابر افزايش يافت. نتيجه يك مطالعه نيز نشان داد كه با ليا

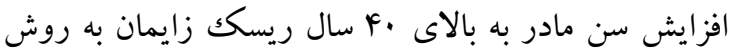

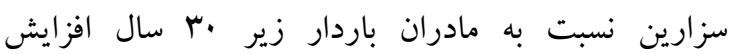
مى يابد(19). در مطالعه حاضر نيز احتمال تولد نوزاد كموزن در تولد سزارين 1/9 برابر بيشتر از تولد به روش طبيعى بود. نتايج مطالعه حاضر نشان داد استعمال دخانيات و استفاده از مواد مخدر هريكك بهتنهايى شانس كموزنى نوزاد هنگام تولد را سه برابر افزايش مىدهد. بررسى ساير مطالعات نيز

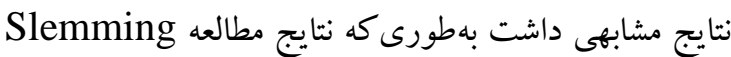

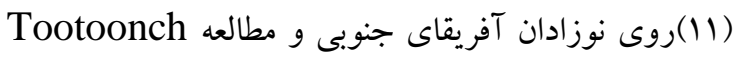
(IN) نشان داد كه مصرف تنباكو با تولد نوزاد كموزن

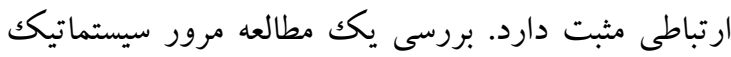
نيز نشان داد كه سيكار مستقل از نزاد مىتواند باعث تولد

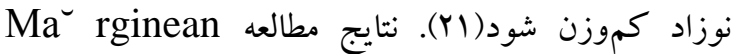

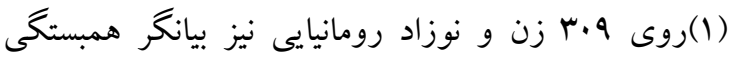
منفى بين وزن هنگام تولد نوزاد و سيكار كشيدن مادر بود. بعلاوه در مطالعه كوهورت Robinson و همكاران(r) در اسبانيا استعمال دخانيات علاوه بر اينكه باعث تولد نوزاد كموزن شد بر وزن كودك در سالهاى بعد نيز اثر كذار بود يكى از دلايل احتمالى اين امر رامىتوان به كليكويروتئين. هورمون جنسى (SHBG) نسبت داد. اين كليكويروتئين در كبد توليدشده و وظيفه حمل هورمونهاى جنسى در خون را بر عهده دارد. مطالعات نشان داده است كه اين يروتئين بهطور معكوس با بافت جربى و مقاومت به انسولين

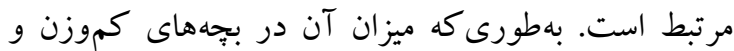
جوانان مبتلابه سندرم متابوليك كاهش مىيابد(Y)). علاوه بر اين مواد مضر موجود در تنباكو و ساير مواد مخدر

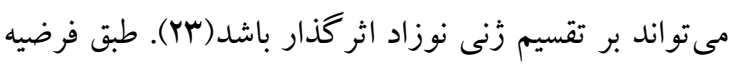

${ }^{4}$ Sex Hormone Binding Globulin 
و Mohammad تحصيلات با بروز نوزاد كموزن ارتباط داشت. كه اين امر مىتو اند به دليل ارتباط تحصيلات با افزايش آكاهى مادر و

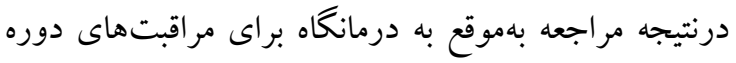

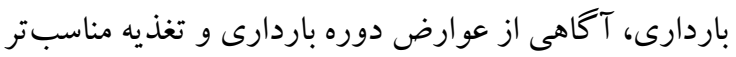

از نقاط قوت اين مطالعه مى توان به نوع مطالعه و حجم نمونه

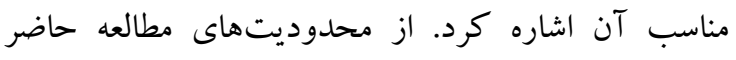
ناقص بودن يروندههاى بهداشتى مادران باردار به دليل

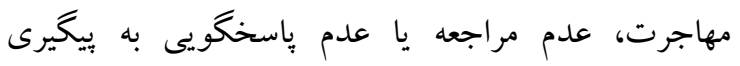

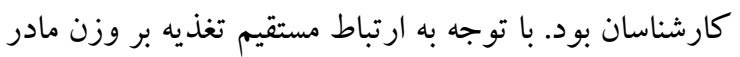
بيشنهاد مى شود كه در مطالعات بعدى دريافت رزيمى مادر

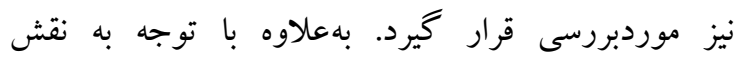
ريزمغذىها در سلامت مادر و جنين ييشنهاد مى شود سطح برخى از ريزمغذىها از قبيل ويتامين دى و آهن نيز مورد

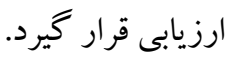

\section{نتيجه كيرى}

نتايج اين مطالعه نشان داد كه براى بيشخيرى از تولد نوزاد كموزن توجه به سن مادر و ييشخيرى از باردارى در سنين بالا، آموزش به مادران در خصوص عدم مصرف بهو مواد مخدر و دخانيات و افزايش تعداد مراقبتهاى حين باردارى مى تواند اقدامات مناسبى در اين زمينه باشد.

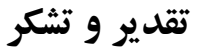

از همكارى كاركنان مراكز بهداشتى درمانى شهرستان جيرفت در جمع آورى اطلاعات قدردانى و تشكر مى شود ده.
هرجه سن بدر بيشتر و قدكوتاهتر احتمال تولد نوزاد كموزن

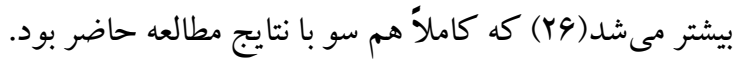

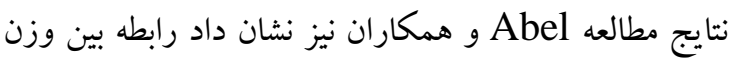

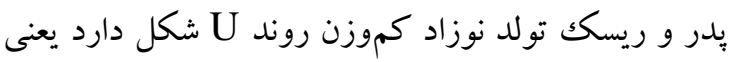
در دو سر طيف سنى احتمال تولد نوزاد كموزن بيشتر

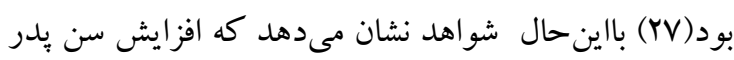

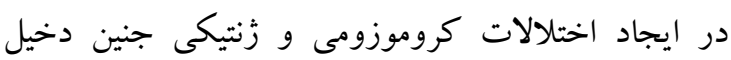

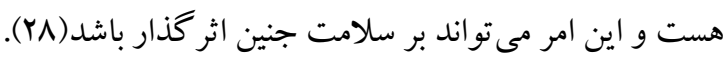
نتايج مطالعه حاضر نشان داد با هر بار مراقبت مادر شانس

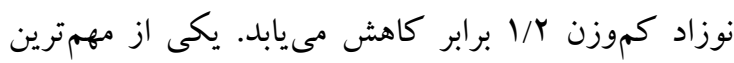

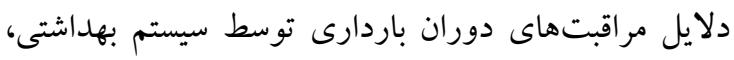

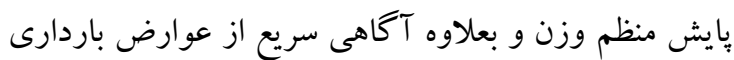
از قبيل ديابت، فشارخون و... است. اين نتيجه همسو با ساير

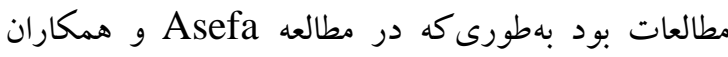
مراقبت بيش از F بار بر وزن گيرى مناسب باردارى مؤثر

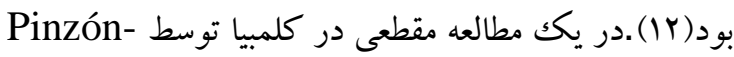
Rondón مر اقبت زمان باردارى توسط سيستم بهداشتى يكى از عوامل

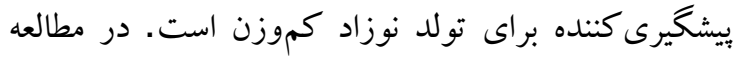

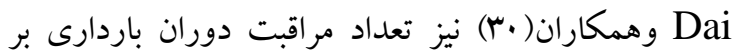
تولد نوزاد كموزن اثر محافظتى داشت. نتايج مطالعه حاضر نشان داد مادران با تحصيلات دييلم

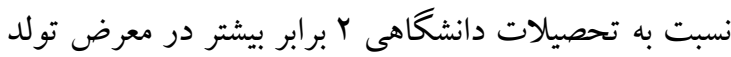
نوزاد كموزن قرار دارند. در مطالعه lshibly و همكاران نيز تحصيلات مادر با وزن تولد نوزاد ارتباط داشت بهورى كه با افزايش تعداد سالهاى تحصيل مادر ريسك

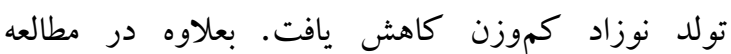

\section{Reference}

1. Mărginean C, Mărginean CO, Bănescu C, Meliţ L, Tripon F, Iancu M. Impact of demographic, genetic, and bioimpedance factors on gestational weight gain and birth weight in a Romanian population. Medicine (Baltimore) 2016; 95: e4098.

2. World Health Organization (WHO). Global Nutrition Targets 2025: Low birth weight policy brief. WHO 2014: 1-8.

3. Momeni M, Esfandyarpour R, Danaei M. The neglected sociobehavioral risk factors of low birth weight. Soc Determ Heal 2016; 1: 97-103. 
4. Unicef. Undernourishment in the womb can lead to diminished potential and predisposes infants to early death. New York: United Nations Children's Fund; 2014. Available from: http://data.unicef.org/nutrition/low-birthweight.

5. Momeni M, Danaei M, Kermani AJN, Bakhshandeh M, Foroodnia S, Mahmoudabadi Z, et al. Prevalence and risk factors of low birth weight in the Southeast of Iran. Int J Prev Med 2017; 8: 12. 6. Mathews TJ, MacDorman MF. Infant mortality statistics from the 2004 period linked birth/infant death data set. Natl Vital Stat Rep. 2007; 55: 1-32.

7. Barker DJP. The developmental origins of chronic adult disease. Acta Paediatr 2004; 93: 26-33.

8. Morrison KM, Ramsingh L, Gunn E, Streiner D, Van Lieshout R, Boyle M, et al. Cardiometabolic health in adults born premature with extremely low birth weight. Pediatrics 2016; 138: e20160515.

9. Stein LJ, Cowart BJ, Beauchamp GK. Salty taste acceptance by infants and young children is related to birth weight: longitudinal analysis of infants within the normal birth weight range. Eur $\mathbf{J}$ Clin Nutr 2006; 60: 272.

10. Abel KM, Wicks S, Susser ES, Dalman C, Pedersen MG, Mortensen PB, et al. Birth weight, schizophrenia, and adult mental disorder: is risk confined to the smallest babies?. Arch Gen Psychiatry 2010; 67: 923-30.

11. Slemming W, Bello B, Saloojee H, Richter L. Maternal risk exposure during pregnancy and infant birth weight. Early Hum Dev 2016; 99: 31-6.

12. Asefa F, Nemomsa D. Gestational weight gain and its associated factors in Harari Regional State: Institution based cross-sectional study, Eastern Ethiopia. Reprod Health 2016; 13: 101.

13. Robinson O, Martínez D, Aurrekoetxea JJ, Estarlich M, Somoano AF, Íñiguez C, et al. The association between passive and active tobacco smoke exposure and child weight status among Spanish children. Obesity 2016; 24: 1767-77.

14. Płotka J, Narkowicz S, Polkowska Ż, Biziuk M, Namieśnik J. Effects of addictive substances during pregnancy and infancy and their analysis in biological materials. Rev Environ Contam Toxicol 2014; 227: 55-77.

15. Kramer MS. Determinants of low birth weight: methodological assessment and meta-analysis. Bull World Health Organ 1987; 65: 663.

16. Kheirouri S, Alizadeh M. Impact of Prenatal Maternal Factors and Birth Order on the Anthropometric Status of Newborns in Iran. J Biosoc Sci 2017; 49: 251-64.

17. Mohammad K, Kassab M, Gamble J, Creedy DK, Foster J. Factors associated with birth weight inequalities in Jordan. Int Nurs Rev 2014; 61: 435-40.

18. Tootoonchi P. Low birth weight among newborn infants at Tehran hospitals. Iran J Pediatr 2007;

17: 186-92. [In Persian]

19. Canto MJ, Reus A, Cortés S, Ojeda F. Pregnancy outcome in a Spanish population of women beyond age 40 delivered above 32 weeks' gestation. J Matern Neonatal Med 2012; 25: 461-6.

20. Fukuda S, Tanaka Y, Harada K, Saruwatari A, Kitaoka K, Odani K, et al. High Maternal Age and Low Pre-Pregnancy Body Mass Index Correlate with Lower Birth Weight of Male Infants. Tohoku J Exp Med 2017; 241: 117-23.

21. Pereira PP da S, Da Mata FAF, Figueiredo ACG, de Andrade KRC, Pereira MG. Maternal active smoking during pregnancy and low birth weight in the americas: A systematic review and metaanalysis. Nicotine Tob Res 2017; 19: 497-505.

22. Dharashivkar S, Wasser L, Baumgartner RN, King JC, Winters SJ. Obesity, maternal smoking and SHBG in neonates. Diabetol Metab Syndr 2016; 8: 1-7.

23. Chen ZY, Yao Y. A synergistic negative effect of gestational smoke-exposure and small litter size on rat placental efficiency, vascularisation and angiogenic factors mRNA expression. PLoS One 2017; 12: 1-11.

24. Haugen M, Brantsæter AL, Winkvist A, Lissner L, Alexander J, Oftedal B, et al. Associations of pre-pregnancy body mass index and gestational weight gain with pregnancy outcome and postpartum weight retention: a prospective observational cohort study. BMC Pregnancy Childbirth 2014; 14: 201. 25. Mcdonald SD, Han Z, Mulla S, Lutsiv O, Lee T. High Gestational Weight Gain and the Risk of Preterm Birth and Low Birth Weight: A Systematic Review and Meta-Analysis. J Obstet Gynaecol 
Can 2011; 33: 1223-33.

26. Shah PS. Paternal factors and low birthweight, preterm, and small for gestational age births: a systematic review. Am J Obstet Gynecol 2010; 202: 103-23.

27. Abel EL, Kruger M, Burd L. Effects of Maternal and Paternal Age on Caucasian and Native American Preterm Births and Birth Weights. Amer J Perinatol 2002;19:49-54.

28. Ramasamy R, Chiba K, Butler P, Lamb DJ. Male biological clock: a critical analysis of advanced paternal age. Fertil Steril 2015;103:1402-6.

29. Pinzón-Rondón ÁM, Gutiérrez-Pinzon V, Madriñan-Navia H, Amin J, Aguilera-Otalvaro P, Hoyos-Martínez A. Low birth weight and prenatal care in Colombia: a cross-sectional study. BMC Pregnancy Childbirth 2015; 15: 118.

30. Dai LL, Mao YY, Luo XM, Shen YP. Prenatal care in combination with maternal educational level has a synergetic effect on the risk of neonatal low birth weight: New findings in a retrospective cohort study in Kunshan City, China. PLoS One 2014; 9: 1-13. 